\title{
CDISC SDTM Device Events Category Terminology
}

National Cancer Institute

\section{Source}

National Cancer Institute. CDISC SDTM Device Events Category Terminology. NCI

Thesaurus. Code C111109.

Terminology associated with the device events category codelist of the Clinical Data

Interchange Standards Consortium (CDISC) Study Data Tabulation Model (SDT M). 